\title{
A retroactive spatial cue improved VSTM capacity in mild cognitive impairment and medial temporal lobe amnesia but not in healthy older adults
}

\author{
Rachel N. Newsome ${ }^{\mathrm{a}, *}$, Audrey Duarte ${ }^{\mathrm{b}}$, Carson Pun ${ }^{\mathrm{a}}$, Victoria M. Smith ${ }^{\mathrm{a}}$, \\ Susanne Ferber ${ }^{\mathrm{a}, \mathrm{c}, 1}$, Morgan D. Barense ${ }^{\mathrm{a}, \mathrm{c}, 1}$ \\ ${ }^{a}$ Department of Psychology, University of Toronto, 100 St. George Street, Toronto, Ont., Canada M5S $3 G 3$ \\ ${ }^{\mathrm{b}}$ School of Psychology, Georgia Institute of Technology, Atlanta, GA, USA \\ ${ }^{\mathrm{c}}$ Rotman Research Institute, Toronto, Ont., Canada
}

\section{A R T I C L E I N F O}

\section{Article history:}

Received 14 May 2015

Received in revised form

30 July 2015

Accepted 19 August 2015

Available online 20 August 2015

Keywords:

Attention

Mild cognitive impairment (MCI)

Aging

Visual short-term memory

Medial temporal lobe (MTL)

Amnesia

Interference

Retrocue

change detection

Binding

\begin{abstract}
A B S T R A C T
Visual short-term memory (VSTM) is a vital cognitive ability, connecting visual input with conscious awareness. VSTM performance declines with mild cognitive impairment (MCI) and medial temporal lobe (MTL) amnesia. Many studies have shown that providing a spatial retrospective cue ("retrocue") improves VSTM capacity estimates for healthy young adults. However, one study has demonstrated that older adults are unable to use a retrocue to inhibit irrelevant items from memory. It is unknown whether patients with MCI and MTL amnesia will be able to use a retrocue to benefit their memory. We administered a retrocue and a baseline (simultaneous cue, "simucue") task to young adults, older adults, MCI patients, and MTL cases. Consistent with previous findings, young adults showed a retrocue benefit, whereas healthy older adults did not. In contrast, both MCI patients and MTL cases showed a retrocue benefit - the use of a retrocue brought patient performance up to the level of age-matched controls. We speculate that the patients were able to use the spatial information from the retrocue to reduce interference and facilitate binding items to their locations.
\end{abstract}

(c) 2015 Elsevier Ltd. All rights reserved.

\section{Introduction}

Visual short-term memory (VSTM) is a critical cognitive ability, allowing for maintenance of visual information for a brief period of time after that information is no longer present in the environment. It is considered to be the visual storage element of working memory, and is limited in capacity to roughly three to four items for simple visual stimuli in healthy young adults (Cowan, 2001; Luck and Vogel, 1997; Todd and Marois, 2004; Vogel and Machizawa, 2004). VSTM performance declines in both healthy aging (Vaughn and Hartman, 2009; Verhaeghen and Salthouse, 1997), mild cognitive impairment (MCI), (Alescio-Lautier, et al., 2007), and following medial temporal lobe (MTL) damage (Ezzyat and Olson, 2008; Olson et al., 2006; Pertzov, et al., 2013).

VSTM capacity is typically measured using a change detection

\footnotetext{
* Corresponding author. Fax: +1 4169784811.

E-mail address: rachel.newsome@mail.utoronto.ca (R.N. Newsome).

${ }^{1}$ These authors contributed equally to the manuscript
}

task, where participants view an array of simple visual items to be remembered (memory array). Following a short delay, participants view a second array (probe array) and indicate whether the probe is identical to the memory array. A large body of evidence suggests that the use of a retroactive cue (retrocue) presented after viewing the memory array, but before the probe array, improves VSTM performance in younger adults (Duarte, et al., 2013; Kuo et al., 2014; Landman et al., 2003; Lepsien et al., 2005; Lepsien and Nobre, 2007; Makovski and Jiang, 2007). The retrocue signals the to-be-probed location and thus indicates that all other uncued items and locations are irrelevant. In a typical retrocue paradigm, performance on the retrocue condition is compared to a baseline condition in which there is either no cue, or a cue appears simultaneously with the probe array (simucue).

Why is the retrocue beneficial? Since the initial retrocue work was published over 10 years ago, there has been debate in the literature as to the precise mechanisms at play (Gazzaley and Nobre, 2012; Gozenman et al., 2014; Griffin and Nobre, 2003; Kuo, et al., 2014; Lepsien, et al., 2005; Makovski and Jiang, 2007, 2008; Makovski et al., 2008; Pinto et al., 2013; Sligte, Scholte and Lamme, 2008; Souza and Oberauer, 2014). One suggestion is that the 
retrocue works by reducing inter-item interference - focusing attention on one critical item during the delay period enhances memory for that critical item by releasing memory interference from other items (Souza et al., 2014). That is, following the retrocue, uncued items from the initial memory representation can be deemed irrelevant and be deleted. An additional explanation is that the retrocue works by reducing probe interference - specifically, focusing attention on a critical item during the maintenance period helps to solidify memory for that item, which makes it more resistant to interference from the probe array (Makovski et al., 2008). The retrocue appears at a time of minimal visual input and when the only task requirement is to maintain an internal representation of the previously seen stimulus. By providing the location that will be probed, attention can reduce the volatility of the representation and make it more durable, akin to "vulcanization," a term that has been used to describe protecting a VSTM representation (Vogel et al., 2006). In contrast, the simucue does not appear until the probe array when competing task demands and visual stimuli divert attention.

Although the two above explanations differ in terms of the origin of interference (i.e., interference from all items vs. interference specific to the probe), both are in agreement that at the heart of the retrocue benefit lies a reduction in interference. Given this, it may be theoretically informative to consider how the retrocue modulates VSTM performance in cases with increased vulnerability to interference. Here we investigated the retrocue benefit in three participant groups with diminished VSTM capacity and heightened susceptibility to interference: older adults, patients with MCI and cases with MTL amnesia. Each of these populations will be discussed in turn below.

One prominent theory, inhibitory deficit theory, proposes a mechanism for reduced VSTM capacity in older adults: According to this theory, older adults have difficulties deleting task-irrelevant information from working memory and are thus susceptible to interference (Hasher et al., 2007; Hasher and Zacks, 1988; Lustig et al., 2007). Indeed, many studies have shown that older adults are more affected by irrelevant information than young adults because they are unable to inhibit it (Amer and Hasher, 2014; Biss et al., 2013; Biss et al., 2013; Healey et al., 2013; Lustig et al., 2007; Weeks and Hasher, 2014). Under this view, one might expect that older adults will not benefit from the retrocue because they are unable to use the cue to resolve inter-item interference from the memory array. That is, even though the retrocue signals items that can be removed from memory, older adults will be unable to benefit from this information because they have problems deleting irrelevant items from an internally represented memory array. Consistent with this notion, the one study that has examined the effects of a retrocue in aging found that older adults did not show an increase in VSTM capacity with the retrocue, in contrast to the well-documented retrocue benefits observed in younger adults (Duarte et al., 2013). That said, on other measures, there was evidence that the retrocue did benefit older adults to some extent: older adults had faster reaction times (RT) on retrocue than noncue trials and also showed modulated electrophysiological responses on retrocue trials (contralateral delay activity, CDA, a measure typically associated with VSTM capacity). Specifically, the CDA observed in older adults was attenuated after the retrocue, suggesting that the retrocue reduced memory load.

Turning to MCI and MTL amnesia, accumulating evidence suggests that patients with MCI and MTL amnesia have compromised VSTM (Alescio-Lautier, et al., 2007; Ezzyat and Olson, 2008; Jiang et al., 2000; Olson et al., 2006; Parra et al., 2009; Parra et al., 2010; Pertzov et al., 2013; Redel et al., 2010). One study suggested that patients with MTL damage showed intact VSTM for individual items, but were impaired at binding the item's identity with its location (Pertzov et al., 2013). Similar binding deficits occur in
Alzheimer's disease patients and cognitively intact persons with the E280A presenilin-1 mutation, commonly termed "familial Alzheimer's disease" (Della Sala et al., 2012; Parra et al., 2009; Parra et al., 2010). It is possible that the spatial information provided by the retrocue may help to ameliorate these deficits by facilitating access to the location information. In addition, recent evidence suggests that both MCI patients and MTL amnesics may be disproportionately vulnerable to interference relative to their age-matched counterparts. Indeed, recent work has shown that removing irrelevant visual information altogether improves performance on memory tasks (Dewar et al. 2014; Dewar et al., 2010; Dewar et al., 2009; Dewar et a, 2015), as well as perceptual discrimination tasks (Barense et al., 2012a; Newsome et al., 2012). Thus, to the extent that MCI patients and MTL amnesia cases can use spatial information from the retrocue to reduce interference from irrelevant items, it may disproportionately benefit their performance relative to that observed in age-matched controls. That is, although the patients' overall capacity may be lower than controls, their retrocue performance may exceed their own baseline simucue performance because they can use the spatial cue to counteract their binding deficits and vulnerability to interference.

To our knowledge, there have been no investigations of retrospective attention in MCI or MTL amnesia, and it remains an open question as to whether the retrocue could confer a VSTM benefit to these patients. Here we tested these ideas by assessing retrospective attention in VSTM to four participant groups: young adults, healthy older adults, older adults with amnestic MCI, and older adults with MTL amnesia. We investigated the effect of the retrocue in two ways: absolute performance (in terms of capacity estimates and RT) and the percent benefit conferred by the retrocue relative to the baseline simucue condition (for both capacity and RT). In short, we confirmed previous results that healthy old adults did not benefit from the retrocue and we report the novel finding that memory-impaired cases showed a disproportionate retrocue benefit, which brought their absolute capacity estimates up to that of healthy older adults' retrocue performance. These results are consistent with inhibitory deficit theory of aging, and suggest that there may be different mechanisms by which these distinct groups use the retrocue.

\section{Material and methods}

\subsection{Participants}

We recruited four groups of participants: younger adults, older adults, MCI patients, and MTL amnesia cases. Fourteen younger adults $\left(M_{\text {age }}=21.50\right.$ years, $S D=1.99, \quad M_{\text {education }}=15.29$ years, $\mathrm{SD}=1.26$ ) were recruited from undergraduate courses at the University of Toronto and 19 healthy older adults $\left(M_{\text {age }}=65.68\right.$ years, $\mathrm{SD}=4.79, \quad M_{\text {education }}=16.47$ years, $\mathrm{SD}=3.67, \quad M_{\mathrm{MoCA}}=27.78$, $\mathrm{SD}=1.55$ ) were recruited from the University of Toronto Adult Volunteer Pool. The young and older adult groups did not differ in education, $t(31)=1.16, p=0.26, d=0.40$.

In addition to these healthy participants, nine patients with clinically diagnosed amnestic MCI were recruited through the Emory University Alzheimer's Disease Research Center. All patients had a full neuropsychological workup and consensus diagnosis from a group of neuropsychologists (see Table 1 for neuropsychological test results). Of these nine patients, one was excluded for having both a perfect score on the Montreal Cognitive Assessment, MoCA (Nasreddine et al., 2005) and a score well within the normal range on the Mini Mental Status Exam, MMSE, (Folstein et al. 1975). This patient has not attended or sought services from the memory clinic for the entire five year period following experimental testing, leading us to believe he was 
Table 1

Demographic information and raw scores from the neuropsychological battery administered to the MCI patients and MTL cases.

\begin{tabular}{|c|c|c|c|c|c|c|c|c|c|c|}
\hline Measure & MCI 1 & MCI 2 & MCI 3 & MCI 4 & MCI 5 & MCI 6 & MCI 7 & MCI 8 & LD & DA \\
\hline Age & 65 & 68 & 61 & 50 & 78 & 64 & 55 & 76 & 62 & 61 \\
\hline Education & 14 & 15 & 12 & 21 & 16 & 13 & 18 & 18 & 19 & 17 \\
\hline Gender & $\mathrm{F}$ & M & $\mathrm{F}$ & $\mathrm{M}$ & $\mathrm{M}$ & $\mathrm{F}$ & M & $\mathrm{F}$ & M & M \\
\hline Diagnosis subtype/etiology & Amn, Lang & Amn & Amn, Lang & $\begin{array}{l}\text { Amn, Exec fx, } \\
\text { Vis-spatial }\end{array}$ & $\begin{array}{c}\text { Amn, Exec } \\
\text { fx }\end{array}$ & Amn & $\begin{array}{l}\text { Amn, Lang, } \\
\text { Exec fx }\end{array}$ & Amn, Lang & $\begin{array}{l}\text { Left temporal lobe } \\
\text { resection }\end{array}$ & Encephalitis \\
\hline MMSE (/30) & 24 & 23 & 28 & 30 & 28 & 30 & 30 & 30 & - & - \\
\hline MoCA (/30) & - & - & 23 & 26 & 25 & 27 & 25 & 25 & 23 & - \\
\hline CDR & 0.5 & 0.5 & 0.5 & 0.5 & 0 & 0.5 & 0.5 & 0.5 & - & - \\
\hline GDS & 1 & 7 & 2 & 1 & 2 & 1 & 3 & - & - & - \\
\hline BDI & 4 & - & 1 & 5 & - & 2 & 12 & - & - & - \\
\hline JOLO & 16 & - & 20 & - & 22 & 20 & 24 & - & - & - \\
\hline Logical memory I & $15(-0.16)$ & $5(-2.70)$ & $14(0.26)$ & $16(0.27)$ & $11(-0.78)$ & $6(-2.40)$ & $9(-96)$ & $14(-0.33)$ & 10 & 7 \\
\hline Logical memory II & $13(-0.33)$ & $4(-2.39)$ & $12(0.12)$ & $15(0.26)$ & $10(-0.67)$ & $5(-2.13)$ & $8(-1.82)$ & $13(-0.23)$ & 2 & 1 \\
\hline BVMT-R total Recall & $16(-1.10)$ & - & $25(0.40)$ & $14(-2.10)$ & $15(0.90)$ & $13(-1.60)$ & $13(-2.00)$ & - & - & - \\
\hline BVMT-R delay Recall & $5(-1.50)$ & - & $9(0.20)$ & $7(-2.20)$ & $5(-1.10)$ & $6(-1.10)$ & $5(-1.90)$ & - & - & - \\
\hline CVLT word list delay & $2(-3.69)$ & $3(-1.71)$ & $5(-1.81)$ & $5^{1}$ & $5(-0.30)$ & $6(-1.19)$ & $6(-0.48)$ & $7(-0.05)$ & 3 & 0 \\
\hline WAIS-R similarities & $20(0.33)$ & - & $17(0.00)$ & $22(0.67)$ & $19(0.33)$ & $16(-0.33)$ & $19(0.00)$ & - & & \\
\hline WAIS-R digit symbol & $45(0.00)$ & $36(0.00)$ & $66(-0.80)$ & - & $37(0.00)$ & $54(0.67)$ & $64(1.00)$ & $59(2.00)$ & & \\
\hline WAIS-R full scale IQ & - & - & - & - & - & - & - & - & 111 & 117 \\
\hline Trails A & $46(0)$ & $34(-0.4)$ & $52(-1.20)$ & - & $48(-1.00)$ & $35(-0.50)$ & $15(1.90)$ & $27(0.7)$ & - & - \\
\hline Trails B & $117(0)$ & $171(-1.80)$ & $162(-1.90)$ & - & $102(-0.10)$ & $75(-0.40)$ & $43(1.10)$ & $53(1.30)$ & - & - \\
\hline Verbal fluency: FAS & $23(-1.90)$ & - & $30(-0.80)$ & $53(0.40)$ & $24(-1.50)$ & $33(-1.00)$ & $47(0.10)$ & - & 8 & 8 \\
\hline Animal category & $19(-0.30)$ & $17(-0.20)$ & $16(-0.80)$ & $28(0.90)$ & $10(-2.30)$ & $23(0.80)$ & $34(2.30)$ & $18(-0.50)$ & - & - \\
\hline Boston naming test & $25(-1.60)$ & $30(2.40)$ & $21(-1.80)$ & - & $25(-0.90)$ & $25(-1.30)$ & $25(-1.80)$ & $18(-2.40)$ & 0 & 10 \\
\hline Digits forward & $6(-0.92)$ & $10(1.41)$ & $7(-0.39)$ & $10(0.88)$ & $9(-0.33)$ & $9(0.52)$ & $11(1.55)$ & $11(2.33)$ & - & - \\
\hline Digits backward & $5(-0.50)$ & $6(0.25)$ & $4(-0.99)$ & $11(2.33)$ & $3(-0.33)$ & $5(-0.50)$ & $10(1.65)$ & $9(2.33)$ & - & - \\
\hline Clock drawing & $11(0.52)$ & $12(1.63)$ & $13(2.74)$ & $5(-9.16)$ & $8(-0.69)$ & $13(2.74)$ & $13(3.48)$ & $13(1.54)$ & - & - \\
\hline Wisconsin card sort & - & - & - & - & - & - & - & - & 6 & 6 \\
\hline Rey-O copy & - & - & - & - & - & - & - & - & 3 & 18 \\
\hline Rey-O delay & - & - & - & - & - & - & - & - & 8 & 0 \\
\hline
\end{tabular}

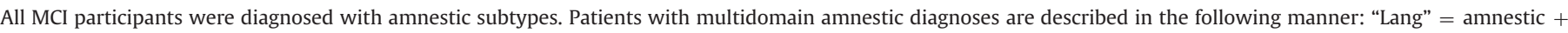
language, "Exec fx" = amnestic + executive function, "Vis-spatial" = amnestic + visuospatial.

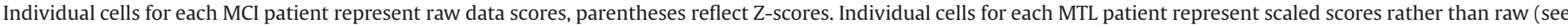
Kwan et al., 2015).

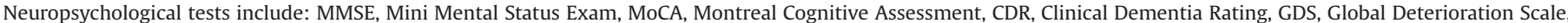

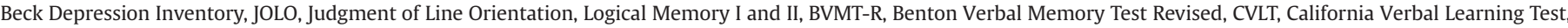
WAIS-R, Wechsler Adult Intelligence Scales - Revised, Boston Naming Test, Digits Forward, Digits Backward; and Clock Drawing Test.

Note: For LD, the Hopkins Verbal Learning Test was administered rather than the CVLT.

"worried well" (Ahmed et al., 2008). Of the remaining eight patients (four female, $M_{\text {age }}=64.63$ years, $S D=9.56$ ), all presented with an amnestic diagnosis (see Table 1 for subtype breakdown). The MCI patients and healthy older adults did not differ in age or education, $t(25)$ 's $<0.41, p$ 's $>0.68$.Fig. 1

Two amnesic cases, DA and LD, with documented MTL damage participated in the study. These patients were recruited through Baycrest Hospital's MemoryLink Program. Both DA and LD have been described previously (Kwan et al., 2015; Rosenbaum et al., 2008). Both patients had severe deficits in memory performance as evidenced by standard neuropsychological tests (see Table 1) and circumscribed lesions to the MTL (Fig. 2). DA was 61 years old at the time of experimental testing and has 17 years of education. Following herpes encephalitis, DA incurred bilateral MTL damage, with more pronounced damage on the right hemisphere. LD was 62 years old at the time of testing, with 19 years of education. LD had a surgical resection of his left temporal lobes secondary to a history of seizures. DA and LD did not differ from the healthy older adult group in terms of age or education, Crawford's $t(19)$ 's $<1.21$, p's $>0.12$.

All participants provided informed consent and were compensated for their time and travel expenses. The study was approved by the Ethics Review Boards of Georgia Institute of Technology, Emory University, Baycrest Hospital and the University of Toronto.

\subsection{Experimental design}

This paradigm was modeled from Experiment 3 of Makovski et al. (2008). Participants were presented with a memory array followed by a probe array after a brief delay and were asked to indicate whether the stimulus in the probe array was the same color as the stimulus that had occupied that location previously seen in the memory array (Error! Reference source not found.) There were two conditions: retrocue and a simultaneous cue (simucue) that served as a baseline. In both conditions, a memory array appeared on screen for $1000 \mathrm{~ms}$, and contained between one and six colored circles. The circles were $1.31^{\circ}$ in diameter, and their colors were chosen from a library of nine colors: brown $(R G B=115$, $69,56)$, red $(R G B=218,37,29)$, orange $(R G B=231,120,23)$, yellow $(R G B=248,195,0)$, green $(R G B=0,146,63)$, light blue $(R G B=0$, $124,195)$, dark blue $(R G B=40,22,111)$, purple $(R G B=144,30$, $120)$, and pale gray $(R G B=220,220,220)$. These stimuli were displayed equidistant from the center, on an imaginary circle with a diameter of $5^{\circ}$. After the memory array, a blank delay screen appeared for $1000 \mathrm{~ms}$. In retrocue trials, after the blank screen, a white arrow appeared in the center of the screen for $100 \mathrm{~ms}$, which directed attention to the to-be-probed location. This arrow always pointed to the location that would later be probed $(100 \%$ valid). After a $400 \mathrm{~ms}$ delay, the single probed item was displayed. In contrast, in simucue trials, the probed item was displayed simultaneously with the white arrow pointing to the probe. The white arrow served as the cue in both conditions. Participants indicated whether the probed item matched the item from that location in the memory array. Equal numbers of simucue and retrocue trials were presented for each of the six set sizes, with $50 \%$ of the probed items matching the stimulus from the memory display (i.e., "same" trials). There were 25 trials for each 


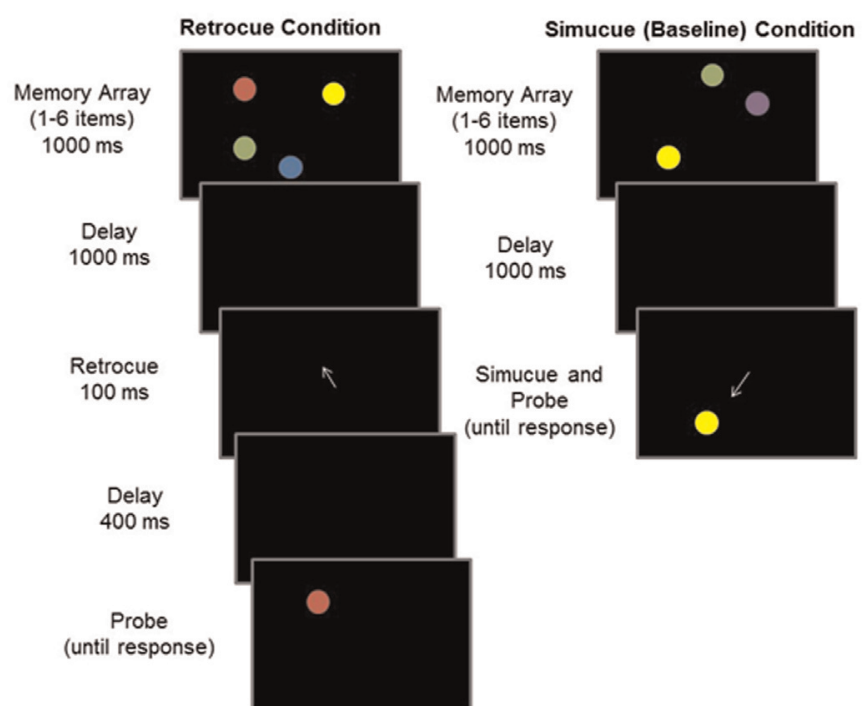

Fig. 1. Schematic of the experimental design, with example stimuli from each condition. In both retrocue and simucue trials, a memory array appeared on screen for $1000 \mathrm{~ms}$. This memory array contained between one and six colored circles (i.e., there were six set sizes in total). This was followed in both conditions by a delay period of $1000 \mathrm{~ms}$. In retrocue trials, an arrow pointing to the to-be probed location was displayed for $100 \mathrm{~ms}$. Here, the arrow is directing attention to the location which previously contained a red circle. After a $400 \mathrm{~ms}$ delay, a probe is displayed, and participants decide whether the color of the object is the same or different than the color of the object in that location previously. In contrast, in simucue trials, the probe and cue appeared simultaneously. Both of the above are examples of "same" trials. (For interpretation of the references to color in this figure legend, the reader is referred to the web version of this article.)

combination of cue type (i.e., retrocue or simucue), set size (i.e., $1-$ $6)$, and response type (i.e., "same" or "different" trials), making a total of 600 trials. The experiment was divided into 10 blocks of 60 trials each. Participants could take a break between each block of trials, and all trial types were randomized.

In retrocue trials, the cue appeared retroactively after the memory array but before the probe, whereas in simucue trials, the cue appeared simultaneously with the probe. As such, in simucue trials the cue did not serve to enhance performance but simply to equate perceptual input across the two conditions. Thus, the simucue condition allowed for an assessment of baseline VSTM performance, to which we could compare any enhancements due to the retrocue. Participants were instructed to remember all of the items presented in the memory array, and that the cue would indicate with $100 \%$ accuracy which item would be tested. Participants were encouraged to respond as quickly and as accurately as possible, but were told that speed was not as important as accuracy. We tested six different set sizes $(1,2,3,4,5$, and 6) to allow for comparisons of simucue and retrocue below and above the capacity of VSTM. The task was programmed using Presentation (Version 14.5, www.neuro-bs.com).

\subsection{Planned statistical analysis}

We report two primary performance measures: absolute performance (for both capacity estimates and RT) and retrocue benefit (for both capacity estimates and RT). Thus, there were four primary dependent variables that were each subjected to the analyses described below: (1) absolute capacity in terms of $K$-estimates, (2) capacity retrocue benefit, (3) absolute speed in terms of RT, (4) RT retrocue benefit. We were interested in effects of aging, $\mathrm{MCI}$, and MTL amnesia. As such, we restricted our comparisons to young vs. older adults (Aging), older adults vs. $\mathrm{MCI}$ (MCI), and older adults vs. MTL amnesics (MTL Amnesia). We planned to perform mixed-design ANOVAs comparing group, set size, and cue (if applicable) for each of these dependent variables and we planned to perform independent samples t-tests to follow up any significant interactions. We predicted retrocue benefits to be greatest once capacity had been reached. We defined capacity as maximum $K$-estimate of the simucue. As such, we split our followup $t$-tests into low set sizes that did not exceed capacity for any group (1-2), and high set sizes (3-6) that exceeded capacity. For all analyses, we report Greenhouse-Geisser corrections where appropriate.

\subsubsection{Absolute performance analysis}

To examine VSTM performance, we calculated memory capacity estimates $(K)$, where $K$ is defined by the formula provided by Cowan (2001):

\section{$K=$ set size $\times$ (hits - false alarms)}

Separate $K$-estimates were computed for each participant, cue type (i.e., retrocue or simucue), and set size (i.e., 1-6). Additionally, RTs were collected for each participant, cue type, and set size. These K-estimates and RT data were submitted to the analyses described below.

\subsubsection{Retrocue percent benefit analysis}

For both $\mathrm{K}$-estimates and RTs we calculated a measure of the benefit from the use of a retrocue relative to the simucue baseline, using the following formulas:

$$
\text { Capacity benefit }=\frac{K_{\text {retrocue }}-K_{\text {simucue }}}{K_{\text {retrocue }}+K_{\text {simucue }}} \times 100
$$
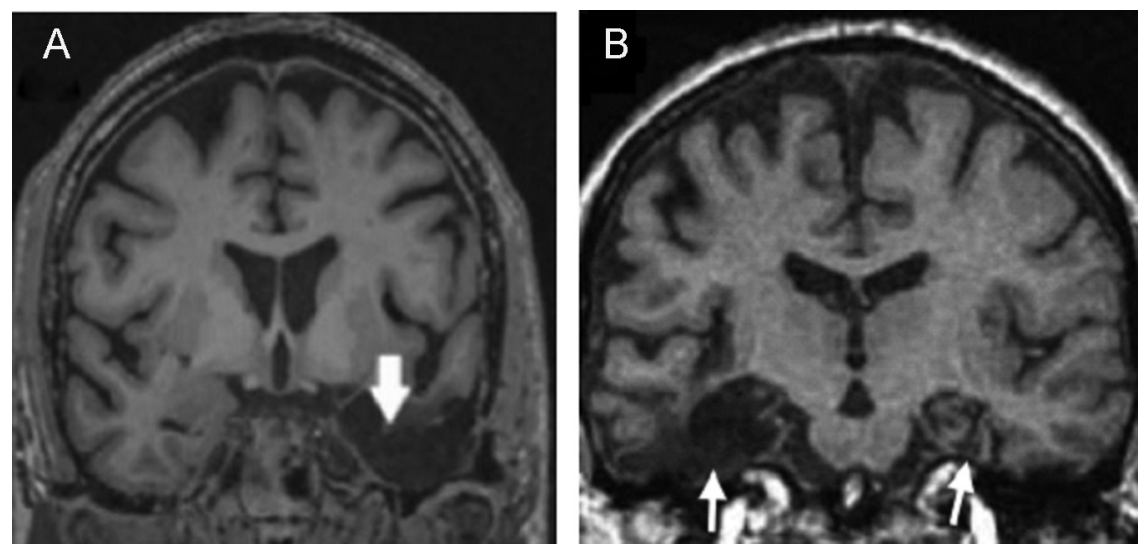

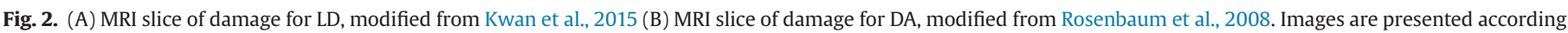
to radiological convention (right hemisphere displayed on left side of image). 
Reaction time benefit $=-\frac{R T_{\text {retrocue }}-R T_{\text {simucue }}}{R T_{\text {retrocue }}+R T_{\text {simucue }}} \times 100$

These calculations normalized each participant's retrocue benefit to his or her overall capacity, thus allowing the comparison of increases across groups. For both formulas, a positive percent benefit score reflects improved performance - either in terms of increased K-estimates or faster RTs - from the use of a retrocue. These data were submitted to ANOVAs to investigate MCI patients and controls as described below.

\subsubsection{MTL patient analysis}

Given that there were only two MTL cases, these data were not suitable for parametric statistical tests. Instead we used Crawford's modified $t$-tests to compare each patient to the older adult control group on each of the four dependent variables described above (Crawford and Garthwaite, 2007).

\section{Results}

\subsection{Absolute capacity (K-estimates)}

\subsubsection{Aging}

We conducted a 2 (group: young adults and older adults) $\times 2$ (cue: retrocue and simucue) $\times 6$ (set size: $1-6$ ) mixed-design ANOVA on the K-estimates shown in Fig. 3 and Table 2. All main effects and interactions were significant: main effects of cue, $F(1$, $31)=34.77, p<0.001, \eta_{p}{ }^{2}=0.53$, set size, $F(2.23,69.09)=154.39$, $p<0.001, \eta_{p}{ }^{2}=0.83$, and group, $F(1,31)=7.58, p=0.01, \eta_{p}{ }^{2}=0.20$, and interactions of cue $\times$ group, $F(1,31)=11.61, p=0.002$, $\eta_{p}{ }^{2}=0.27$, set size $\times$ group, $F(2.23,69.09)=11.57, \quad p<0.001$, $\eta_{p}{ }^{2}=0.27$, cue $\times$ set size, $F(2.49,77.06)=8.92, p<0.001, \eta_{p}{ }^{2}=0.22$. The critical three-way cue $\times$ set size $\times$ group interaction was also significant, $F(2.49,77.06)=4.71, p=0.007, \eta_{p}{ }^{2}=0.13$.

To follow up this interaction, we conducted independent samples $t$-tests across groups at low (1-2) and high (3-6) set sizes for both cue types. These showed that young adults' simucue performance was higher than older adults' simucue performance only at higher set sizes of the retrocue condition, $t(31)=3.80$, $p=0.001, d=1.34$, and marginally at higher set sizes of the simucue condition, $t(31)=1.79, p=0.08, d=0.63$, but not at lower set sizes of either condition, $t(31)$ 's $<1.18, p$ 's $>0.25$, d's $<0.41$.

\subsection{2. $M C I$}

We conducted a 2 (group: older adults, $\mathrm{MCI}) \times 2$ (cue) $\times 6$ (set size) mixed-design ANOVA on the $K$-estimates shown in Fig. 3 and Table 2. This revealed main effects of cue, $F(1,25)=29.41, p<0.001$,

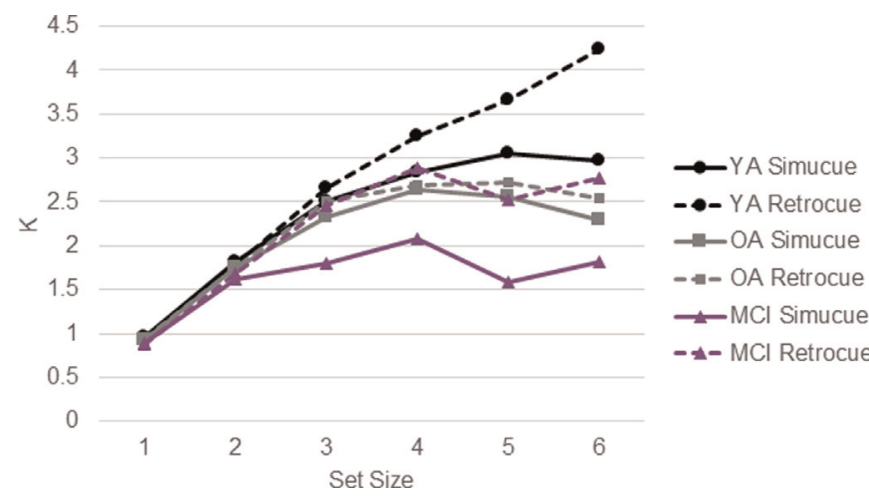

Fig. 3. Absolute capacity in terms of $K$-estimates in younger adults (YA, $N=14$ ) older adults $(\mathrm{OA}, N=19)$ and mild cognitive impairment patients $(\mathrm{MCI}, N=8)$. Our primary finding was that the retro-cue raised MCI VSTM capacity to the level of their age-matched counterparts. $\eta_{p}{ }^{2}=0.54$, set size, $F(2.05,51.32)=53.58, p<0.001, \eta_{p}{ }^{2}=0.68$, a cue $\times$ set size interaction, $F(2.97,74.33)=4.99, p=0.003, \eta_{p}{ }^{2}=0.17$, and a cue $\times$ group interaction, $F(1,25)=13.74, p=0.001, \eta_{p}{ }^{2}=0.36$. Additionally, there was a marginally significant three-way interaction of cue $\times$ set size $\times$ group, $F(2.97,74.33)=2.39, \quad p=0.08$ $\eta_{p}{ }^{2}=0.09$. There were no other significant effects or interactions, $F \mathrm{~s}<1.31, p^{\prime} \mathrm{s}>0.28, \eta_{p}{ }^{2} \mathrm{~s}<0.05$.

To follow up this interaction, we conducted independent samples $t$-tests across groups at low (1-2) and high (3-6) set sizes for both cue types. These revealed that $\mathrm{MCI}$ patients had lower simucue $K$-estimates than older adults at higher set sizes, $t(25)=$ 2.09, $p=0.047, d=0.88$ but $\mathrm{MCI}$ patients did not differ from older adults at any other set size or condition, $t(25)$ 's $<.91, p$ 's $>.37$, d's $<0.38$.

\subsubsection{MTL amnesia}

To compare each MTL case to older adult controls, we used Crawford's modified $t$-tests that compared each patient relative to older adult controls for low (1-2) and high (3-6) set sizes at each cue type (Fig. 4, Table 2). DA showed marginally smaller K-estimates on small set sizes of the simucue condition, $t(18)=1.36$, $p=0.09$, but performance did not significantly differ from controls at any other set size or condition, $t(18)$ 's $<1.05$, $p$ 's $>0.15$. LD did not perform significantly different from controls at any size or condition, $t(18)$ 's $<0.99$, $p$ 's $>0.17$.

\subsection{Retrocue capacity benefit}

To further investigate performance on the retrocue relative to performance on the simucue, we created a percent benefit score that reflected improvements from the retrocue. These data were subjected to the analyses described below.

\subsubsection{Aging}

We performed a 2 (group: young adults, older adults) $\times 6$ (set size) mixed-design ANOVA with percent benefit as the dependent variable (Fig. 5). This revealed main effects of set size, $F(2.60$, $80.44)=4.91, p=0.005, \eta_{p}{ }^{2}=0.14$, group, $F(1,31)=6.31, p=0.02$, $\eta_{p}{ }^{2}=0.17$, and a set size $\times$ group interaction, $F(2.60,80.44)=3.16$, $p=0.04, \eta_{p}{ }^{2}=0.09$. To investigate this interaction, we performed independent samples $t$-tests across groups at low (1-2) and high (3-6) set sizes. These revealed that young adults had a greater retrocue benefit than older adults at higher set sizes, $t(31)=2.90$, $p=0.007, d=1.02$. There was no difference between the groups at low set sizes, $t(31)=1.30, p=0.20, d=0.46$. These results suggest that young adults showed a greater retrocue benefit as set size increased, whereas older adults did not.

We investigated the retrocue benefit relative to zero benefit by performing one sample $t$-tests for each group. Younger adults showed a retrocue benefit greater than zero at higher set sizes, $t$ $(13)=4.95, p<0.001, d=1.32$, but not at low set sizes, $t(13)=1.33$, $p=0.21, d=0.35$. Older adults did not show a retrocue benefit greater than zero at either low or high set sizes, $t(18)$ 's $<1.62$, p's $>.12, d ' s<0.37$.

\subsection{2. $\mathrm{MCI}$}

We performed a 2 (group: older adults, $\mathrm{MCI}) \times 6$ (set size) mixed-design ANOVA with percent benefit as the dependent variable (Fig. 5). This revealed main effects of group, $F(1,25)=$ $12.36, p=0.002, \eta_{p}{ }^{2}=0.33$, set size, $F(2.36,59.14)=6.34, p=0.002$, $\eta_{p}{ }^{2}=0.20$, and a set size $\times$ group interaction, $F(2.36,59.14)=4.89$, $p=0.008, \eta_{p}^{2}=0.16$. To investigate this interaction, we conducted independent samples $t$-tests across groups at low and high set sizes. MCI patients showed a greater retrocue benefit than older adults at set sizes higher set sizes, $t(25)=3.63, p=0.001, d=1.53$, but not at lower set sizes, $t(25)=0.62, p=0.54, d=0.26$. 
Table 2

$K$-estimates for retrocue and simucue performance for each set size and group.

\begin{tabular}{|c|c|c|c|c|c|c|}
\hline Retrocue & Set Size 1 & Set Size 2 & Set Size 3 & Set Size 4 & Set Size 5 & Set Size 6 \\
\hline Younger adults & $\begin{array}{c}0.92 \\
(0.08)\end{array}$ & $\begin{array}{c}1.79 \\
(0.26)\end{array}$ & $\begin{array}{c}2.66 \\
(0.41)\end{array}$ & $\begin{array}{c}3.25 \\
(0.72)\end{array}$ & $\begin{array}{c}3.65 \\
(0.73)\end{array}$ & $\begin{array}{c}4.23 \\
(0.99)\end{array}$ \\
\hline Healthy older adults & $\begin{array}{c}0.94 \\
(0.06)\end{array}$ & $\begin{array}{c}1.75 \\
(0.29)\end{array}$ & $\begin{array}{c}2.50 \\
(0.37)\end{array}$ & $\begin{array}{c}2.70 \\
(0.52)\end{array}$ & $\begin{array}{c}2.72 \\
(0.96)\end{array}$ & $\begin{array}{c}2.54 \\
(0.97)\end{array}$ \\
\hline MCI & $\begin{array}{c}0.87 \\
(2.38)\end{array}$ & $\begin{array}{c}1.68 \\
(2.14)\end{array}$ & $\begin{array}{c}2.46 \\
(2.00)\end{array}$ & $\begin{array}{c}2.88 \\
(1.78)\end{array}$ & $\begin{array}{c}2.53 \\
(2.12)\end{array}$ & $\begin{array}{c}2.77 \\
(2.06)\end{array}$ \\
\hline $\begin{array}{l}\text { LD } \\
\text { DA }\end{array}$ & $\begin{array}{l}0.96 \\
0.96\end{array}$ & $\begin{array}{l}2.00 \\
1.76\end{array}$ & $\begin{array}{l}2.52 \\
2.50\end{array}$ & $\begin{array}{l}3.20 \\
3.52\end{array}$ & $\begin{array}{l}2.94 \\
3.73\end{array}$ & $\begin{array}{l}0.96 \\
3.36\end{array}$ \\
\hline \multicolumn{7}{|l|}{ Simucue } \\
\hline Younger adults & $\begin{array}{c}0.96 \\
(0.04)\end{array}$ & $\begin{array}{c}1.82 \\
(0.22)\end{array}$ & $\begin{array}{c}2.50 \\
(0.45)\end{array}$ & $\begin{array}{c}2.84 \\
(0.77)\end{array}$ & $\begin{array}{c}3.04 \\
(0.94)\end{array}$ & $\begin{array}{c}2.96 \\
(1.08)\end{array}$ \\
\hline Healthy older adults & $\begin{array}{c}0.93 \\
(0.07)\end{array}$ & $\begin{array}{c}1.75 \\
(0.21)\end{array}$ & $\begin{array}{c}2.33 \\
(0.50)\end{array}$ & $\begin{array}{c}2.65 \\
(0.58)\end{array}$ & $\begin{array}{c}2.56 \\
(0.75)\end{array}$ & $\begin{array}{c}2.29 \\
(0.73)\end{array}$ \\
\hline MCI & $\begin{array}{c}0.89 \\
(2.38)\end{array}$ & $\begin{array}{c}1.63 \\
(2.17)\end{array}$ & $\begin{array}{c}1.80 \\
(2.22)\end{array}$ & $\begin{array}{c}2.09 \\
(2.14)\end{array}$ & $\begin{array}{c}1.59 \\
(2.48)\end{array}$ & $\begin{array}{c}1.82 \\
(2.50)\end{array}$ \\
\hline LD & 0.95 & 1.76 & 1.80 & 2.03 & 1.00 & 2.88 \\
\hline DA & 0.85 & 1.50 & 2.50 & 2.72 & 3.18 & 0.72 \\
\hline
\end{tabular}

K-estimates for each set size, condition, and group. Standard deviations are shown in parentheses.

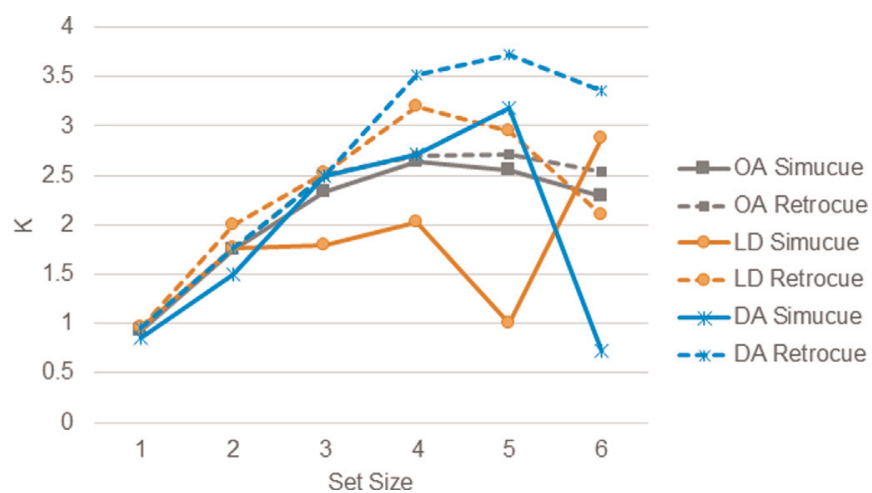

Fig. 4. Absolute capacity in terms of $K$-estimates in older adults $(O A, N=19)$ and medial temporal lobe amnesic cases $(N=2$ : LD and DA).

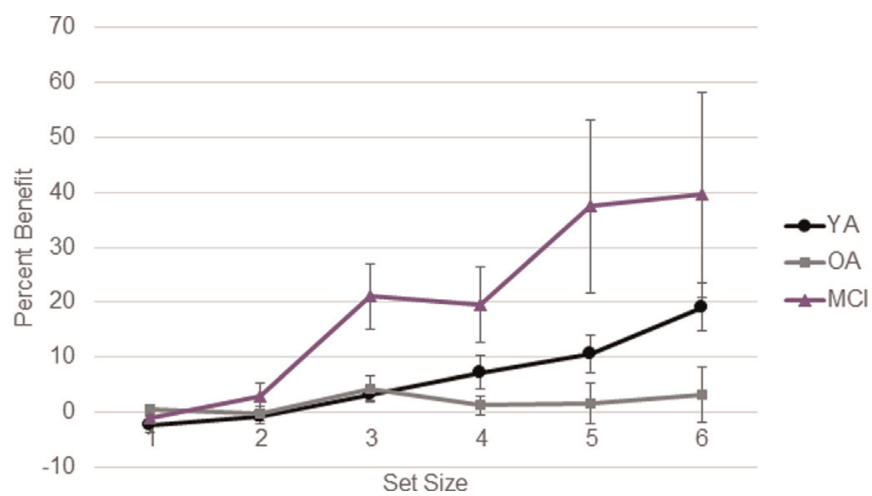

Fig. 5. Percent benefit from use of a retrocue in younger adults $(N=14)$, older adults $(\mathrm{OA}, N=19)$ and mild cognitive impairment patients ( $\mathrm{MCI}, N=8)$. We found that the $\mathrm{MCI}$ patients and younger adults showed a retrocue benefit at higher set sizes, whereas older adults did not show a retrocue benefit. Error bars reflect SEM.

We investigated the retrocue benefit relative to zero benefit by performing one sample $t$-tests for each group, as described above. $\mathrm{MCI}$ patients showed a retrocue benefit greater than zero at higher set sizes, $t(7)=2.67, p=0.03, d=0.94$, but not at low set sizes, $t$ (7) $=0.60, p=0.57, d=0.21$

When considered with the absolute capacity analysis above, these results indicate that $\mathrm{MCI}$ patients had a reduced baseline simucue performance compared to their age-matched controls, and that the retrocue brought their performance up to the level of their healthy counterparts on the same condition.

\subsubsection{MTL amnesia}

We compared the retrocue benefit scores of each MTL case to healthy older adult controls using Crawford's modified $t$-tests (Fig. 6) and found that LD showed a retrocue benefit greater than controls at higher set sizes, $t(19)=2.15, p=0.02$, but not at low set sizes, $t(19)=1.13, p=0.14$. DA showed a retrocue benefit greater than controls at both high and low set sizes, $t(19)$ 's $>2.45$, p's $<0.01$.

\subsection{Absolute speed (RT)}

Reaction times (RTs) were collected for each participant, cue type, and set size. To ensure our effects were not artifacts due to multiplicative slowing (Faust, Balota, Spieler, \& Ferraro, 1999), we performed the same analyses on log-transformed RTs. This did not meaningfully change the results.

\subsubsection{Aging}

We conducted a 2 (group: young adults, older adults) $\times 2$ (cue) $\times 6$ (set size) mixed-design ANOVA with dependent variable of RT (see Table 3 ). This revealed main effects of cue, $F(1,31)=$

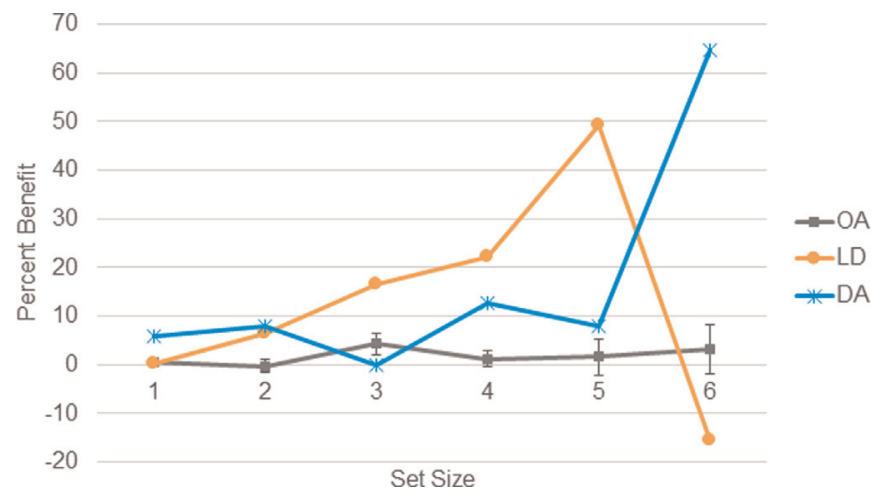

Fig. 6. Percent benefit of retrocue capacity in older adults $(O A, N=19)$ and medial temporal lobe amnesic cases $(N=2$ : LD and DA). Error bars reflect SEM. 
Table 3

RTs for retrocue and simucue performance for each set size and group.

\begin{tabular}{|c|c|c|c|c|c|c|}
\hline Retrocue & Set Size 1 & Set Size 2 & Set Size 3 & Set Size 4 & Set Size 5 & Set Size 6 \\
\hline Younger adults & $\begin{array}{l}578.99 \\
(89.47)\end{array}$ & $\begin{array}{l}584.57 \\
(94.26)\end{array}$ & $\begin{array}{c}598.39 \\
(114.55)\end{array}$ & $\begin{array}{c}627.24 \\
(100.09)\end{array}$ & $\begin{array}{c}630.99 \\
(119.28)\end{array}$ & $\begin{array}{c}656.84 \\
(120.95)\end{array}$ \\
\hline Healthy older adults & $\begin{array}{c}789.63 \\
(121.16)\end{array}$ & $\begin{array}{c}854.78 \\
(161.55)\end{array}$ & $\begin{array}{c}932.69 \\
(175.59)\end{array}$ & $\begin{array}{l}1062.37 \\
(182.14)\end{array}$ & $\begin{array}{l}1117.41 \\
(200.44)\end{array}$ & $\begin{array}{l}1189.90 \\
(227.72)\end{array}$ \\
\hline MCI & $\begin{array}{c}964.41 \\
(216.13)\end{array}$ & $\begin{array}{l}1026.83 \\
(284.73)\end{array}$ & $\begin{array}{l}1010.45 \\
(264.44)\end{array}$ & $\begin{array}{l}1084.87 \\
(213.85)\end{array}$ & $\begin{array}{l}1149.82 \\
(249.57)\end{array}$ & $\begin{array}{l}1157.22 \\
(220.96)\end{array}$ \\
\hline $\begin{array}{l}\text { LD } \\
\text { DA }\end{array}$ & $\begin{array}{c}674.074 \\
1078.7435\end{array}$ & $\begin{array}{l}823.976 \\
872.644\end{array}$ & $\begin{array}{l}913.268 \\
987.87083\end{array}$ & $\begin{array}{c}1047.704 \\
890.31\end{array}$ & $\begin{array}{l}994.84286 \\
896.2\end{array}$ & $\begin{array}{c}1003.4408 \\
929.862\end{array}$ \\
\hline \multicolumn{7}{|l|}{ Simucue } \\
\hline Younger adults & $\begin{array}{c}655.89 \\
(115.03)\end{array}$ & $\begin{array}{l}716.74 \\
(94.29)\end{array}$ & $\begin{array}{l}751.56 \\
(97.47)\end{array}$ & $\begin{array}{l}803.13 \\
(95.59)\end{array}$ & $\begin{array}{l}833.66 \\
(99.69)\end{array}$ & $\begin{array}{l}849.47 \\
(97.06)\end{array}$ \\
\hline Healthy older adults & $\begin{array}{c}902.56 \\
(144.18)\end{array}$ & $\begin{array}{l}1052.62 \\
(140.09)\end{array}$ & $\begin{array}{l}1187.03 \\
(172.06)\end{array}$ & $\begin{array}{l}1257.40 \\
(153.72)\end{array}$ & $\begin{array}{l}1329.79 \\
(180.02)\end{array}$ & $\begin{array}{l}1341.63 \\
(197.36)\end{array}$ \\
\hline MCI & $\begin{array}{l}1087.25 \\
(240.05)\end{array}$ & $\begin{array}{l}1192.90 \\
(278.59)^{a}\end{array}$ & $\begin{array}{l}1284.44 \\
(206.92)\end{array}$ & $\begin{array}{l}1317.97 \\
(260.02)\end{array}$ & $\begin{array}{l}1347.33 \\
(198.02)\end{array}$ & $\begin{array}{l}1357.08 \\
(143.07)\end{array}$ \\
\hline LD & 749.66327 & 1061.526 & 1236.414 & 1304.3531 & 1309.962 & 1277.254 \\
\hline DA & $1330.9195^{*}$ & 1144.6735 & 1074.9816 & 1155.412 & 1152.0143 & 1279.748 \\
\hline
\end{tabular}

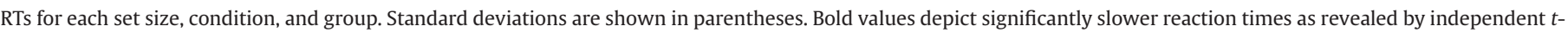
tests comparing healthy older adults vs. MCI patients, or by Crawford's modified $t$-tests comparing LD and DA to controls.

$$
\begin{array}{rl}
* & p<0.05 \\
\text { a } p<0.1
\end{array}
$$

422.88, $p<0.001, \eta_{p}{ }^{2}=0.93$, set size, $F(2.36,73.05)=106.83$, $p<0.001, \quad \eta_{p}{ }^{2}=0.78$, and group, $F(1,31)=71.44, \quad p<0.001$, $\eta_{p}{ }^{2}=0.70$ The following interactions were significant: set size $\times$ group, $F(2.36,73.05)=28.71, p<0.001, \eta_{p}{ }^{2}=0.48$, cue $\times$ set size, $F(3.59,111.29)=11.45, p<0.001, \eta_{p}^{2}=0.27$, and cue $\times$ set size $\times$ group, $F(3.59,111.29)=4.04, p=0.006, \eta_{p}{ }^{2}=0.12$. Finally, we observed a marginal cue $\times$ group interaction, $F(1,31)=3.64$, $p=0.06, \eta_{p}{ }^{2}=0.11$.

Independent samples $t$-tests comparing young and older adults showed that younger adults had faster RTs than older adults at all set sizes and conditions, $t(31)$ 's $>5.73, p$ 's $<.001, d$ 's $>2.02$.

\subsection{2. $\mathrm{Mci}$}

We conducted a 2 (group: older adults, $\mathrm{MCI}) \times 2$ (cue) $\times 6$ (set size) mixed-design ANOVA with dependent variable of RT (Table 3). This revealed main effects of cue, $F(1,25)=316.41, p<0.001$, $\eta_{p}{ }^{2}=.93$, set size, $F(2.20,55.06)=71.95, p<0.001, \eta_{p}{ }^{2}=0.74$, a cue $\times$ set size interaction, $F(3.66,91.50)=7.63, p<0.001, \eta_{p}{ }^{2}=0.23$, and a set size $\times$ group interaction, $F(2.20,55.06)=6.42, p=0.002$, $\eta_{p}{ }^{2}=0.20$. There were no other significant effects or interactions, $F$ s $<1.17, p^{\prime} \mathrm{s}>0.29, \eta_{p}{ }^{2} \mathrm{~s}<0.05$.

Independent samples $t$-tests comparing older adults and $\mathrm{MCI}$ patients showed that older adult controls responded faster than $\mathrm{MCI}$ patients at smaller set sizes of both conditions, $t(25)$ 's $>2.20$, $p$ 's $<0.04, d$ 's $>0.93$. There was no difference in reaction times at higher set sizes of both conditions, $t(25)$ 's $<0.65, p$ 's $>0.52$, d's $>0.28$.

\subsubsection{MTL amnesia}

We compared individual RTs of the MTL cases to controls using Crawford's modified $t$-tests and found DA was slower than controls only at lower set sizes of the simucue condition, $t(19)=1.95$, $p=0.03$, but not at any other set sizes or conditions, $t(19)$ 's $<1.09$, $p$ 's $>0.15$. LD's RTs were not different from controls at any condition or set size, $t(19)$ 's $<0.54, p$ 's $>0.30$.

\subsection{Retrocue RT benefit}

\subsubsection{Aging}

The retrocue RT benefit data were subjected to a 2 (group: young adults, older adults) $\times 6$ (set size) mixed-design ANOVA with dependent variable of RT percent benefit. This revealed a main effect of set size, $F(3.51,108.81)=10.12, p<0.001, \eta_{p}{ }^{2}=0.25$, a marginal main effect of group, $F(1,31)=3.83, p=0.06, \eta_{p}{ }^{2}=0.11$, and a set size $\times$ group interaction, $F(3.51,108.81)=6.81, p<0.001$, $\eta_{p}{ }^{2}=0.18$. To investigate the interaction, we conducted independent samples $t$-tests across groups at high and low set sizes. These revealed that young adults had a greater retrocue RT percent benefit than older adults at higher set sizes, $t(31)=2.61$, $p=0.01, d=0.92$, but not at lower set sizes, $t(31)=0.37, p=0.71$, $d=0.13$.

\subsection{2. $\mathrm{MCI}$}

The RT percent benefit data were subjected to a 2 (group: older adults, $\mathrm{MCI}) \times 6$ (set size) mixed-design ANOVA with dependent variable of retrocue RT percent benefit. This revealed a main effect of set size, $F(3.47,86.74)=6.96, p<0.001, \eta_{p}{ }^{2}=0.22$, with no other significant effects or interactions, $F \mathrm{~s}<1.14, p^{\prime} \mathrm{s}>.34, \eta_{p}{ }^{2} \mathrm{~s}>.04$. These analyses suggest that retrocue benefit RT slowed as set size increased for both groups. In other words, as set size increased, relative RT speed gains from the retrocue diminished.

\subsubsection{MTL amnesia}

As above, we compared retrocue benefit RT scores for individual amnesic cases using Crawford's modified $t$-tests. These statistics showed that both LD's and DA's retrocue RT percent benefit was not different from controls at any set size, $t$ (19)'s $<1.07, p$ 's $>0.14$.

\section{Discussion}

In the present study, we administered a VSTM task and manipulated the presence of a spatial retroactive cue (retrocue) versus a baseline cue that was presented simultaneously with the 
probe array (simucue). To our knowledge, we provide the first evidence that patients with MCI and MTL amnesia benefited from a spatial retroactive cue. The use of a retrocue brought patient performance up to the level of healthy older adult controls, effectively eliminating their deficit on the simucue condition. This pattern of performance manifested as a larger retrocue benefit for patients than healthy older participants. These results provide novel evidence that retroactively cueing spatial attention improved VSTM performance in MCI and MTL amnesia. Consistent with previous research, heathy young adults showed a retrocue benefit, and healthy older adults did not show a retrocue benefit. These effects emerged at higher, but not lower, set sizes. All groups showed faster RTs for retrocue than simucue trials.

Why is it that healthy older adults do not benefit from the retrocue, whereas the MCI and MTL patients, who are also older adults, do benefit? Firstly, it is important to emphasize that patients almost never outperformed their aged-matched counterparts, but they were able to derive a greater benefit from the use of the retrocue. We speculate that the patients and healthy older adults responded to the retrocue in different ways. Consistent with inhibition deficit theory described above (Hasher et al., 2007; Hasher and Zacks, 1988; Lustig et al., 2007), older adults do not benefit from a retrocue because they are unable to use it to inhibit irrelevant items from the memory representation, which makes them susceptible to interference from extraneous items in the memory array and/or interference caused by the probe. In fact, our results replicate the only known published study on the retrocue effect in aging (Duarte et al., 2013). More specifically, in this earlier study, older adults showed no retrocue benefit in terms of capacity, but did show a faster reaction time for retrocue trials. It was suggested that older adults used the retrocues to facilitate priming of perceptual and/or motor networks associated with target detection.

Why did the patients' accuracy estimates benefit from the retrocue? The present task requires a participant to identify whether a specific item occurred in a specific location. Previous research has suggested that such item-location binding is particularly impaired in MCI and MTL amnesia (Pertzov et al., 2013). We hypothesize that the retrocue may help to overcome these itemlocation binding deficits by providing a critical piece of information: the location. In contrast to the simucue, which also provides location information after the memory array, the retrocue provides location information when there are no other concurrent task demands or exogenously presented stimuli.

We speculate that having no competing mental operations or visual representations is critical to the retrocue being effective. Under these circumstances of low interference, attention can be focused on the critical item and memory for it strengthened (Makovski et al., 2008). Our previous work suggests that the memory impaired cases in the present study may be particularly vulnerable to interference from a barrage of visual information (Barense et al. 2012a; Newsome et al., 2012). The previous tasks assessed object representation using a perceptual discrimination task with complex novel objects. We interpreted the results in the context of a recent model suggesting that simple, low-level features of objects are represented in posterior regions of the ventral visual stream, whereas complex feature conjunctions are represented in more anterior regions, with the perirhinal cortex in the MTL representing the conjunctions of features comprising an entire object (Cowell et al., 2010). In the present study, we are not taxing object representation, but rather putting an object in space, which is thought to be dependent on the hippocampus, the next level of representational complexity (Lee et al., 2012). Both the perirhinal and hippocampal cortices are damaged in the patient groups in the present study, which may lead to similar vulnerabilities to interference across vastly diverse tasks (i.e., VSTM with simple color circles versus perceptual discrimination with complex novel objects).

In this sense, the retrocue provides a cue to an otherwise impoverished or vulnerable representation of a critical feature: location. We speculate that strengthening the representation of this spatial information, and thus reducing spatial interference, is fundamental to the improved patient performance. That is, MCI and MTL patients have impaired spatial binding abilities, and may be able to use the additional spatial information from the retrocue to facilitate binding items to their locations to counteract their binding deficits (Pertzov et al., 2013), whereas healthy older adults' reduced VSTM capacity is not thought to be affected by binding (Pertzov et al. in press). However, the MCI and MTL patients are also older adults and experience the same inhibitory control deficits associated with aging (Hasher and Zacks, 1988). As such, whereas their performance on the retrocue condition improved relative to their performance on the simucue condition, it did not exceed that of their older adult controls.

We speculate that we are measuring different kinds of interference, which may be well-suited to further investigation with different experimental controls. Specifically, interference reduction may occur in deleting irrelevant information, or it may occur in terms of solidifying, or protecting a particularly vulnerable representation. Future experiments could adjudicate these mechanisms. For example, in the current study, stimuli were chosen from a limited library of nine colors repeated across 600 trials, leading to large amounts of proactive interference (Gazzaley and Nobre, 2012). Employing trial-unique stimuli would mitigate this interference build-up to some extent. More specifically, if the older adult deficit is due to problems deleting irrelevant information, we might expect better performance on conditions employing trialunique, compared to repeating, stimuli. Additionally, we hypothesized that patients' retrocue benefit was due in part to the fact that they used it to ameliorate weak binding abilities. To test this more directly, we could use non-location retrocues such as color (Li \& Saiki, 2014) to evaluate how critical item-location binding is for the retro-cue benefit in memory-impaired patients.

Finally, these findings add to a growing body of literature suggesting that the MTL is not only important for aspects of longterm memory (Squire and Zola-Morgan, 1991), but also important for other aspects of cognition, including VSTM. Consistent with our findings, Olson and colleagues found that the hippocampus was critical for object-location working memory at short delays of 8 seconds (Olson et al., 2006). Similarly, Hannula and colleagues found that hippocampal amnesia patients were impaired at detecting relations between objects at short lags, with 3 seconds between stimulus displays (Hannula et al., 2006). These effects may occur on even shorter timescales. Indeed, Lu and colleagues found that iconic memory was impaired in $\mathrm{MCI}$ patients at a delay of less than $100 \mathrm{~ms}$ (Lu et al., 2005). Similarly, VSTM deficits have been seen in Alzheimer's disease patients immediately following the presentation of a stimulus (i.e., no delay), in a task where participants were asked to name the stimulus that they had just seen (Della Sala et al., 2012). Even more striking, deficits in these patient groups have been observed on perceptual tasks which have no delay at all (Barense et al., 2012b; Newsome, et al., 2012). As further evidence that these effects are not delay dependent, in the current study, the time delay between memory array and probe was greatest in the retrocue condition (retrocue: $(1000 \mathrm{~ms}$ delay $+100 \mathrm{~ms}$ retrocue $+400 \mathrm{~ms}$ delay $)=1500 \mathrm{~ms}$ versus simucue: $1000 \mathrm{~ms}$ delay). This was also the condition in which performance was the most accurate.

In conclusion, we found novel evidence that $\mathrm{MCI}$ patients and MTL amnesic cases were able to use a retrocue to improve their VSTM capacity estimates to the level of healthy controls. Consistent with previous findings, we also found that young adults 
had a retrocue benefit, but older adults did not. We postulate that the spatial information provided by the retrocue reduced interference and facilitated binding in the memory-impaired cases, which brought their performance to the level of their healthy older adult counterparts.

\section{Acknowledgments}

This work was supported by the Canadian Institutes of Health Research through grants to M.D. Barense (115148) and S. Ferber (106436), and from the Emory Alzheimer's Disease Research Center, Emory University Grant (2P50AG025688-06). We would like to thank all participants for their involvement and Maha Adamo for her help with task piloting.

\section{References}

Ahmed, S., Mitchell, J., Arnold, R., Dawson, K., Nestor, P.J., Hodges, J.R., 2008. Memory complaints in mild cognitive impairment, worried well, and semantic dementia patients. Alzheimer's Dis. Assoc. Disord. 22, 227-235.

Alescio-Lautier, B., Michel, B., Herrea, C., Elahmadi, A., Chambon, C., Touzet, C., Paban, V., 2007. Visual and visuospatial short-term memory in mild cognitive impairment and Alzhiemer's disease: role of attention. Neuropsychologia 45, 1948-1960.

Amer, T., Hasher, L., 2014. Conceptual processing of distractors by older but not younger adults. Psychol. Sci. 25, 2252-2258.

Barense, M.D., Groen, I.I., Lee, A.C., Yeung, L.-K., Brady, S.M., Gregori, M., Kapur, N., Bussey, T.J., Saksida, L.M., Henson, R.N., 2012. Intact memory for irrelevant information impairs perception in amnesia. Neuron 75, 157-167.

Barense, M.D., Ngo, K.J., Hung, L.H., Peterson, M.A., 2012. Interactions of memory and perception in amnesia: the figure-ground perspective. Cereb. Cortex 22, 2680-2691.

Biss, R.K., Campbell, K.L., Hasher, L., 2013. Interference from previous distraction disrupts older adults' memory. J. Gerontol. Ser. B: Psychol. Sci. Soc. Sci. 68, 558-561.

Biss, R.K., Ngo, K.J., Hasher, L., Campbell, K.L., Rowe, G., 2013. Distraction can reduce age-related forgetting. Psychol. Sci. 24, 448-455.

Cowan, N., 2001. The magical number 4 in short-term memory: a reconsideration of mental storage capacity. Behav. Brain Sci. 24, 87-185.

Cowell, R.A., Bussey, T.J., Saksida, L.M., 2010. Why does brain damage impair memory? A connectionist model of object recognition memory in perirhinal cortex. J. Neurosci. 26, 12186-12197.

Crawford, J.D., Garthwaite, P.H., 2007. Comparison of a single case to a control or normative sample in neuropsychology: development of a Bayesian approach. Cogn. Neuropsychol. 24, 343-372.

Della Sala, S., Parra, M.A., Luzzi, S., Abrahams, S., 2012. Short-term memory binding is impaired in AD but not in non-AD dementias. Neuropsychologia 50, 833-840.

Dewar, M., Alber, J., Cowan, N., Della Sala, S., 2014. Boosting long-term memory via wakeful rest: intentional rehearsal is not necessary, consolidation is sufficient. PLoS One 9, e109542.

Dewar, M., Della Sala, S., Beschin, N., Cowan, N., 2010. Profound retroactive interference in anterograde amnesia: what interferes? Neuropsychology 24 , 357-367.

Dewar, M., Garcia, Y.F., Cowan, N., Della Sala, S., 2009. Delaying interference enhances memory consolidation in amnesic patients. Neuropsychology 23, 627-634.

Dewar, M., Hoefeijzers, S., Zeman, A., Butler, C., Della Sala, S., 2015. Impaired picture recognition in transient epileptic amnesia. Epilepsy Behav. 42, 107-116.

Duarte, A., Hearons, P., Jiang, Y., Delvin, M.C., Newsome, R.N., Verhaeghen, P., 2013. Retrospective attention enhances visual working memory in the young, but not the old: an ERP study. Psychophysiol. 50, 465-476.

Ezzyat, Y., Olson, I.R., 2008. The medial temporal lobe and visual working memory: comparisons across tasks, delays, and visual similarity. Cogn. Affect. Behav. Neurosci. 8, 32-40.

Faust, M.E., Balota, D.A., Spieler, D.H., Ferraro, F.R., 1999. Individual differences in information-processing rate and amount: implications for group differences in response latency. Psychol. Bull. 125, 777-799.

Folstein, M.F., Folstein, S.E., McHugh, P.R., 1975. "Mini-Mental State" a practical method for grading the cognitive state of patients for the clinician. J. Psychiatr. Res. 12, 189-198.

Gazzaley, A., Nobre, A.C., 2012. Top-down modulation: bridging selective attention and working memory. Trends Cogn. Sci. 16, 129-135.

Gozenman, F., Tanoue, R.T., Metoyer, T., Berryhill, M.E., 2014. Invalid retrocues can eliminate the retrocue benefit: evidence for a hybridized account. J. Exp. Psychol. Hum. Percept. Perform. 40, 1748-1754, http://www.ncbi.nlm.nih.gov/ pubmed/25045904.

Griffin, I.C., Nobre, A.C., 2003. Orienting attention to locations in internal representations. J. Cogn. Neurosci. 15, 1176-1194.
Hannula, D.E., Tranel, D., Cohen, N.J., 2006. The long and the short of it: relational memory impairments in amnesia, even at short lags. J. Neurosci. 26, 8352-8359.

Hasher, L., Lustig, C., Zacks, R.T., 2007. Inhibitory mechanisms and the control of attention. In: Conway, A., Jarrold, C., Kane, M., Miyake, A., Towse, A., Towse, J. (Eds.), Variation in Working Memory, pp. 146-162.

Hasher, L., Zacks, R.T., 1988. Working memory, comprehension, and aging: a review and a new view. In: Bower, G. (Ed.), The Psychology of Learning vol. 22. Academic Press, New York, pp. 193-225.

Healey, M.K., Hasher, L., Campbell, K.L., 2013. The role of suppression in resolving interference: evidence for an age-related deficit. Psychol. Aging 28, 721-728.

Jiang, Y., Olson, I.R., Chun, M.M., 2000. Organization of visual short-term memory. J. Exp. Psychol.: Learn., Mem. Cogn. 26, 683-702.

Kuo, B.-C., Stokes, M.G., Murray, A.M., Nobre, A.C., 2014. Attention biases visual activity in visual short-term memory. J. Cogn. Neurosci. 26, 1377-1389.

Kwan, D., Craver, C.F., Green, L., Myerson, J., Gao, F., Black, S.E., Rosenbaum, S.R., 2015. Cueing the personal future to reduce discounting in intertemporal choice: is episodic prospection necessary? Hippocampus 25, 432-443.

Landman, R., Spekreijse, H., Lamme, V.A., 2003. Large capacity storage of integrated objects before change blindness. Vis. Res. 43, 146-164.

Lee, A.C., Yeung, L.-K., Barense, M.D., 2012. The hippocampus and visual perception. Front. Hum. Neurosci. 6, 91.

Lepsien, J., Griffin, I.C., Devlin, J.T., Nobre, A.C., 2005. Directing spatial attention in mental representations: interactions between attentional orienting and working-memory load. NeuroImage 26, 733-743.

Lepsien, J., Nobre, A.C., 2007. Attentional modulation of object representations in working memory. Cereb. Cortex 17, 2072-2083.

Li, Q., Saiki, J., 2014. The effects of sequential attention shifts within visual working memory. Front. Psychol. 5, 1-10.

Lu, Z.-L., Neuse, J., Madigan, S., Dosher, B.A., 2005. Fast decay of iconic memory in observers with mild cognitive impairments. Proc. Natl. Acad. Sci. 102, 1797-1802.

Luck, S.J., Vogel, E.K., 1997. The capacity of visual working memory for features and conjunctions. Nature 390, 279-281.

Lustig, C., Hasher, L., Zacks, R.T., 2007. Inhibitory deficit theory: Recent developments in a "new view". In: Gorfein, D., MacLeod, C. (Eds.), The place of inhibition in cognition. American Psychological Association, Washington, DC, pp. $145-162$.

Makovski, T., Jiang, Y., 2007. Distributing versus focusing attention in visual shortterm memory. Psychon. Bull. Rev, 14, 1072-1078.

Makovski, T., Jiang, Y., 2008. Proactive interference from items previously stored in visual working memory. Mem. Cogn. 36, 43-52.

Makovski, T., Sussman, R., Jiang, Y., 2008. Orienting attention in visual working memory reduces interference from memory probes. J. Exp. Psychol.: Learn., Mem. Cogn. 34, 369-380.

Nasreddine, Z.S., Phillips, N.A., Bedirian, V., Charbonneau, S., Whitehead, V., Collin, I., Cummings, J.L., Chertkow, H., 2005. The montreal cognitive assessment, MoCA: a brief screening tool for mild cognitive impairment. J. Am. Geriatr. Soc. 53, 695-699.

Newsome, R.N., Duarte, A., Barense, M.D., 2012. Reducing perceptual interference improves visual discrimination in mild cognitive impairment: implications for a model of perirhinal cortex function. Hippocampus 22, 1990-1999.

Olson, I.R., Page, K., Moore, K.S., Chatterjee, A., Verfaellie, M., 2006. Working memory for conjunctions relies on the medial temporal lobe. J. Neurosci. 26, 4596-4601.

Parra, M.A., Abrahams, S., Fabi, K., Logie, R., Luzzi, S., Della Sala, S., 2009. Short-term memory binding deficits in Alzheimer's disease. Brain, 1-10.

Parra, M.A., Abrahams, S., Logie, R.H., Mendez, L.G., Lopera, F., Della Sala, S., 2010. Visual short-term memory binding deficits in familial Alzheimer's disease. Brain 133, 2702-2713.

Pertzov, Y., Heider, M., Liang, Y., Husain, M., 2015. Effects of healthy ageing on precision and binding of object location in visual short-term memory. Psych Aging. 30 (1), 26-35, 10.1037/a0038396.

Pertzov, Y., Miller, T.D., Gorgoraptis, N., Caine, D., Schott, J.M., Butler, C., Husain, M. 2013. Binding deficits in memory following medial temporal lobe damage in patients with voltage-gated potassium channel complex antibody-associated limbic encephalitis. Brain, 1-12.

Pinto, Y., Sligte, I.G., Shapiro, K.L., Lamme, V.A., 2013. Fragile visual short-term memory is an object-based and location-specific store. Psychon. Bull. Rev. 20, 732-739.

Redel, P., Bublak, P., Sorg, C., Kurz, A., Forstl, H., MUller, H., Schneider, W., Perneczky, R., Finke, K., 2010. Deficits of spatial and task-related attentional selection in mild cognitive impairment and Alzheimer's disease. Neurobiol. Aging.

Rosenbaum, S.R., Moscovitch, M., Foster, J.K., Schnyer, D.M., Gao, F., Kovacevic, N., Verfaellie, M., Black, S.E., Levine, B., 2008. Patterns of autobiographical memory loss in medial temporal lobe amnesic patients. J. Cogn. Neurosci. 20, 1490-1506.

Sligte, I.G., Scholte, H.S., Lamme, V.A., 2008. Are there multiple visual short-term memory stores? PLoS One 3, 1-9.

Souza, A.S., Rerko, L., Oberauer, K., 2014. Unloading and reloading working memory: Attending to one item frees capacity. J. Exp. Psychol.: Hum. Percep. Perform. 40, 1237-1256.

Squire, L.R., Zola-Morgan, S., 1991. The medial temporal lobe memory system. Science 253, 1380-1386.

Todd, J.J., Marois, R., 2004. Capacity limit of visual short-term memory in human posterior parietal cortex. Nature 428, 751-754. 
Vaughn, L., Hartman, M., 2009. Aging and visual short-term memory: Effects of object type and information load. Aging Neuropsychol. Cogn.: J. Norm. Dysfunct. Dev. 17, 35-54.

Verhaeghen, P., Salthouse, T.A., 1997. Meta-analysis of age-cognition relations in adulthood: estimates of linear and nonlinear age effects and structural models. Psychol. Bull. 122, 231-249.

Vogel, E.K., Machizawa, M.G., 2004. Neural activities predicts individual differences in visual working memory capacity. Nature 428, 748-751.

Vogel, E.K., Woodman, G.F., Luck, S.J., 2006. The time course of consolidation in visual working memory. J. Exp. Psychol.: Hum. Percept. Perform. 32, 1436-1451.

Weeks, J.C., Hasher, L., 2014. The disruptive-and beneficial-effects of distraction on older adults' cognitive performance. Front. Psychol. 5. 